\title{
A visão de um fornecedor-chave sobre a colaboração com a montadora
}

\section{Collaboration in the automotive supply chain: a case between automaker and key supplier}

\author{
Carla de Oliveira Siqueira ${ }^{1}$ \\ Gilberto Miller Devós Ganga' ${ }^{1}$ \\ Luis Antonio de Santa-Eulalia ${ }^{2,3}$
}

\begin{abstract}
Resumo: Este trabalho teve como objetivo descrever e discutir os elementos do processo de colaboração entre uma montadora de automóveis e um fornecedor-chave, do ponto de vista deste último. A indústria automotiva muito contribuiu para impulsionar a gestão da cadeia de suprimentos desde os anos 1990, mas a literatura nacional não descreve que patamar de maturidade tal setor industrial alcançou com os principais fornecedores de primeira camada, especialmente sob a ótica do abastecimento. Visando realizar um primeiro passo na compreensão deste fenômeno, utilizou-se do método de estudo de caso exploratório-descritivo. Os resultados indicam a existência de uma colaboração limitada ao nível operacional e de maturidade reduzida. A confiança, um input vital para o sucesso da gestão colaborativa, mostrou-se restrita, evidenciando, em alguns momentos, um comportamento ganha-perde. Pôde-se inferir que o primeiro passo em busca do estabelecimento de um relacionamento colaborativo foi realizado, no entanto existem muitas barreiras a serem superadas na consolidação de um verdadeiro relacionamento colaborativo. Isto ocorre mesmo em um ambiente de empresas ditas de classe mundial e em um setor industrial deveras sofisticado, como o automobilístico.
\end{abstract}

Palavras-chave: Gestão da cadeia de suprimentos; Colaboração orientada ao abastecimento; Indústria automotiva.

\begin{abstract}
This study aims to describe and discuss the elements of the collaboration process between an automaker and a key supplier from the point of view of the latter. The automotive industry has done much to develop the supply chain management field since the 1990s, but the Brazilian literature does not describe the maturity level reached with first-tier key suppliers, especially from the supply-side perspective. To take a first step towards understanding this phenomenon, we used an exploratory-descriptive case study method. Results indicate limited collaboration at the operational level and reduced maturity. Trust, a vital input for the success of collaboration, proved to be restricted, even at times showing a win-lose behavior. It might be inferred that the first step toward the establishment of a collaborative relationship was accomplished; however, many barriers are to be overcome in order to consolidate a true collaborative relationship. This occurs even with world-class companies in a rather sophisticated industrial sector such as the auto industry.
\end{abstract}

Keywords: Supply chain management; Supply-side collaboration; Automotive industry.

\section{Introdução}

De acordo com a Associação Nacional dos Fabricantes de Veículos Automotores (ANFAVEA), o Brasil é o $7^{\circ}$ maior país em produção mundial de veículos, com faturamento de US\$106,8 bilhões em 2012. O país conta com 29 montadoras e aproximadamente 500 fabricantes de autopeças, somando uma capacidade produtiva de aproximadamente 4,5 milhões de veículos. A produção nacional de veículos representou $21 \%$ do PIB industrial em 2012 e empregou 1,5 milhões de pessoas, o que evidencia a grande importância da indústria automobilística na economia do país (ANFAVEA, 2014).

O setor vem passando por grandes transformações desde os anos 1990, principalmente no que diz respeito à definição das novas estratégias de operações para o gerenciamento da cadeia de suprimentos. Dessa forma,

${ }^{1}$ Departamento de Engenharia da Produção, Centro de Ciências Exatas e de Tecnologia, Universidade Federal de São Carlos - UFSCar, CEP 13565-905, São Carlos, SP, Brasil, e-mail: carla.oliveira.siqueira@gmail.com; ganga@dep.ufscar.br

${ }^{2}$ Faculté d'administration, Université de Sherbrooke, J1K2R1, Sherbrooke, Quebec, Canadá, e-mail: luis.antonio.de.santa-eulalia@ usherbrooke.ca

${ }^{3}$ Université Laval, QC G1V 0A6, Québec, Canadá

Recebido em Jun. 6, 2014 - Aceito em Set. 2, 2015

Suporte financeiro: Nenhum. 
a indústria automotiva brasileira vem sendo alvo de várias pesquisas no âmbito da gestão da produção e operações (Thomé et al., 2014; Pereira \& Amatucci, 2014; Carnevalli et al., 2013; Jabbour et al., 2013; Thun \& Hoenig, 2011; Mesquita \& Castro, 2008; Alves et al., 2004; Humphrey, 2003; Pires, 1998).

À medida que as pressões de mercado (e.g., redução nos prazos de entrega e no time to market, maior flexibilidade do mix de produtos) aumentam sobre as montadoras, estas, como resposta, pressionam a sua cadeia de abastecimento a adotarem práticas de gestão que visem promover ganhos de responsividade da cadeia de suprimentos como um todo (Ciravegna et al., 2013; Lockström et al., 2010; Jayaram et al., 2008; Donada, 2001). Assim, o processo de gestão da demanda e gestão do abastecimento por toda a cadeia de suprimentos (Melo \& Alcântara, 2012; Mentzer et al., 2007; Croxton et al., 2002) passa a utilizar como inputs estimativas de vendas e capacidade dos recursos de manufatura, abastecimento e distribuição.

Nesse cenário, práticas corriqueiras de transmissão de estimativas de vendas das montadoras aos fornecedores ocorrem, por exemplo, via EDI (Electronic Data Interchange). Contudo, as estimativas de vendas podem sofrer alterações ao longo do horizonte de planejamento, devido ao grande dinamismo do mercado automobilístico. Os fornecedores, por sua vez, para atender a essa demanda utilizam-se de duas estratégias diferentes. A primeira visa atender às variações de demanda a partir de estoques planejados; já a segunda procura atender à demanda por meio de flexibilidade da capacidade produtiva (i.e., via adequação do programa da produção à previsão de vendas do cliente) (Thun \& Hoenig, 2011). Ambas as estratégias são adotadas por muitas empresas na expectativa de atender às montadoras e, assim, acabam por provocarem grandes flutuações de demanda e estoques ao longo da cadeia produtiva, causando o chamado "efeito chicote" (Roldan \& Miyake, 2004; Lee et al., 1997).

Uma das formas de se reduzir (ou até eliminar) esse efeito indesejado está relacionado à mitigação das incertezas por meio do estabelecimento de um relacionamento colaborativo entre os elos da cadeia de suprimentos, proporcionando uma constante troca de informações, inclusive com relação à demanda real do ponto de venda (Simchi-Levi et al., 2010). Como efeito idiossincrático, passa a ser necessário maior coordenação interfuncional (Rapp et al., 2012; Sousa \& Lengler, 2011; Golicic \& Vitasek, 2007; Min, 2001) e interorganizacional (Esper, 2007).

Assim, as montadoras buscam implantar práticas colaborativas com seus fornecedores-chave (Oh \& Rhee, 2008), pois possuem forte poder de governança no sentido montante, principalmente com os fornecedores de primeira camada (Fleury \& Fleury, 2000). Contudo, para a efetivação das práticas de colaboração, é necessário o desenvolvimento de confiança mútua, comprometimento, integração de processos e de tecnologias de informação e comunicação, entre outros fatores que possibilitem minimizar o risco no processo de abastecimento ou atendimento da demanda, mas que nem sempre estão presentes de forma madura (Simatupang \& Sridharan, 2002, 2005; Kanter, 1994). De forma simples, pode-se dizer que uma colaboração no setor é baseada em elementos explícitos (ações e práticas) de natureza estratégica e tática, bem como elementos intangíveis (Vieira et al., 2009, 2010).

Neste contexto, pesquisas que descrevam e explorem em maior profundidade como ocorrem as práticas colaborativas entre a montadora e seus fornecedores-chave passam a ganhar destaque desde os anos 1990. Por exemplo, fazendo uso da abordagem de estudo de casos múltiplos, Thomé et al. (2014) exploraram os efeitos do conceito de flexibilidade em um ambiente de cadeias multicamadas; Carnevalli et al. (2013), por meio de uma survey, demonstraram que a modularidade na cadeia de suprimentos é uma prática que, apesar de benéfica para a montadora, acaba por transferir custos fixos aos fornecedores; Sacomano et al. (2013) analisaram os arranjos conhecidos como Consórcio Modular e Condomínio Modular do ponto de vista da governança; Vanalle \& Salles (2011) realizaram um estudo sobre as relações entre cliente e fornecedor em empresas do setor automobilístico, concluindo que estas ainda possuem características de um modelo basicamente associativo, baseado em relações contratuais, sendo o preço ainda o principal critério da relação; Rodrigues \& Sellitto (2008) discutiram como um fornecedor de motores colabora com a montadora do ponto de vista de práticas logísticas de integração da cadeia; Pires (1998) apresentou o consórcio modular como um caso radical de colaboração entre uma montadora e sete fornecedores de primeira camada.

No entanto, apesar de todas essas contribuições científicas, no Brasil, esse assunto ainda não foi explorado com a mesma perspectiva deste trabalho. Desta forma, este trabalho objetiva compreender o nível de colaboração entre uma montadora e um grande fornecedor-chave de primeira camada, segundo a visão deste agente, por meio de um estudo de caso exploratório-descritivo. Para tanto, aborda-se o problema do ponto de vista de práticas estratégicas e táticas e elementos intangíveis da relação.

Este estudo não abrange todas as tipologias de colaboração entre um fornecedor e a montadora (Oh \& Rhee, 2008), mas trata de questões como a comunicação colaborativa, compras estratégicas e desenvolvimento de fornecedores, visando a mitigação do risco de ruptura do abastecimento de peças desse fornecedor para a montadora. 
Este trabalho está organizado da seguinte maneira: A Seção 2 traz o modelo teórico-conceitual adotado na pesquisa, ilustrando os constructos a serem explorados. A Seção 3 apresenta a metodologia; enquanto a Seção 4 descreve a empresa estudada e o segmento de mercado em que atua, bem como apresenta e discute o relacionamento colaborativo existente entre o fornecedor-chave estudado e a montadora. Por fim, a Seção 5 apresenta as conclusões acerca da pesquisa realizada e proposições de trabalhos futuros.

\section{Modelo teórico-conceitual}

Um estudo publicado nos EUA (Dannenberg \& Kleinhans, 2007) estimou que em 2015 os fornecedores automotivos representarão cerca de $80 \%$ do total de criação de valor na produção e engenharia de veículos inovadores. Para Dannenberg \& Kleinhans (2007), esta criação de valor refere-se, em maior parte, na capacidade das montadoras e fornecedores-chave de atuarem de forma colaborativa no desenvolvimento de produtos/serviços inovadores e sustentáveis.

No entanto, as práticas de colaboração na cadeia automobilística não se restringem apenas ao desenvolvimento de produtos. Elas envolvem também comunicação colaborativa, solução de problemas de forma conjunta, compra estratégica e desenvolvimento de fornecedores (Oh \& Rhee, 2008). Dessa forma, práticas colaborativas tornam-se um elemento-chave no contexto da gestão da cadeia de suprimentos (Vivaldini et al., 2008).
Típicas formas de colaboração na cadeia de suprimentos envolvem colaboração direcionada ao atendimento da demanda (fluxo jusante), colaboração direcionada ao abastecimento (fluxo montante) e sincronização total (Fu \& Piplani, 2004). Inúmeros estudos exploram a colaboração direcionada ao atendimento da demanda e os benefícios alcançados, tais como redução da ruptura e dos níveis de estoques. Embora os impactos positivos da colaboração direcionada ao abastecimento sejam intuitivamente os mesmos da colaboração direcionado ao atendimento da demanda (jusante), a literatura necessita de maior exploração e identificação dos benefícios e elementos da colaboração montante (Gümüş et al., 2012; Foroughi et al., 2006; Fu \& Piplani, 2004). Este parece ser um problema de outros tempos, mas como será discutido mais à frente, há indícios de que tal problema ainda persista nos dias atuais. Para tanto, este trabalho procurou explorar a visão de um fornecedor-chave sobre o relacionamento colaborativo com a montadora.

O modelo teórico-conceitual adotado na pesquisa buscou definir constructos que representassem os elementos de colaboração na cadeia de suprimentos. Para melhor classificação e estruturação desses elementos, foram adotadas as propostas de Vieira et al. (2009, 2010), tal como resumido no Quadro 1.

Para a proposição desta classificação, esses autores basearam-se em trabalhos clássicos da literatura sobre colaboração em cadeia de suprimentos, de meados da década de 1990 até o ano de 2005. A fim de atualizar o

Quadro 1. Modelo teórico-conceitual.

\begin{tabular}{|c|c|c|c|}
\hline $\begin{array}{l}\text { Elementos de } \\
\text { Colaboração } \\
\text { na cadeia de } \\
\text { suprimentos }\end{array}$ & $\begin{array}{l}\text { Componentes dos elementos } \\
\text { de colaboração na cadeia de } \\
\text { suprimentos }\end{array}$ & $\begin{array}{l}\text { Algumas referências de } \\
\text { Vieira et al. }(2009,2010)\end{array}$ & $\begin{array}{c}\text { Revisão Sistemática da } \\
\text { literatura }\end{array}$ \\
\hline Estratégicos & $\begin{array}{l}\text { Compartilhamento de } \\
\text { informações de estoque, } \\
\text { Conhecimento das estratégias } \\
\text { e dificuldades do parceiro, } \\
\text { Envolvimento da alta gerência. }\end{array}$ & \multirow{3}{*}{$\begin{array}{l}\text { Evans \& Wolf (2005), } \\
\text { Simatupang \& Sridharan } \\
\text { (2002, 2005), Lambert \& } \\
\text { Knemeyer (2004), Xu \& } \\
\text { Dong (2004), Liker \& Choi } \\
\text { (2004), Barratt (2004), } \\
\text { Skjoett-Larsen et al. (2003), } \\
\text { Frankel et al. (2002), } \\
\text { Choi et al. (2002), Nesheim } \\
\text { (2001), Barratt \& Oliveira } \\
\text { (2001), Ireland \& Bruce } \\
\text { (2000), Dyer \& Chu (1996), } \\
\text { Kanter (1994), Mohr \& } \\
\text { Spekman (1994), Morgan } \\
\text { \& Hunt (1994), Anderson \& } \\
\text { Narus (1990). }\end{array}$} & \multirow{3}{*}{$\begin{array}{l}\text { Ramanathan \& Gunasekaran } \\
\text { (2014), Ceryno et al. (2013), } \\
\text { Thomé et al. (2014), } \\
\text { Wu et al. (2014), Neumann } \\
\text { (2012), Roldan et al. (2011), } \\
\text { Neumann et al. (2011), } \\
\text { Sambasivan et al. (2011), } \\
\text { Ambrose et al. (2010), } \\
\text { Ryu et al. (2009), } \\
\text { Sodhi \& Son (2009), Blos et al. } \\
\text { (2009), Mehrjerdi (2009), } \\
\text { Fawcett et al. (2008), } \\
\text { Hadaya \& Cassivi (2007), } \\
\text { Danese (2007), Lee et al. (2007), } \\
\text { Matopoulos et al. (2007), } \\
\text { Maylett \& Vitasek (2007), } \\
\text { Sandberg (2007), Whipple \& } \\
\text { Russell (2007), Vereecke \& } \\
\text { Muylle (2006), Fu \& Piplani } \\
\text { (2004). }\end{array}$} \\
\hline Táticos & $\begin{array}{l}\text { Ações conjuntas, } \\
\text { Compartilhamento de riscos/ } \\
\text { ganhos logísticos, Troca } \\
\text { de informações logísticas e } \\
\text { comerciais. }\end{array}$ & & \\
\hline Intangíveis & $\begin{array}{l}\text { Confiança, Interdependência, } \\
\text { Flexibilidade, Reciprocidade. }\end{array}$ & & \\
\hline
\end{tabular}

Fonte: Baseado em Vieira et al. $(2009,2010)$ e atualizado pelos autores. 
modelo, foi realizada uma busca sistemática na base de dados Web of Science, a qual está resumida na última coluna do Quadro 1. Como parâmetros de busca, utilizou-se alternadamente as seguintes palavras-chave: supply chain and collaboration; supply chain and collaborative; supply chain and partnership (s); supply chain and relationship (s). Os filtros de busca utilizado foram: (a) busca no título da publicação; (b) do ano de 2004 até 2014; (c) coleções utilizadas: Science Citation Index Expanded e Social Sciences Citation Index; (d) somente artigos de periódicos e com texto na íntegra disponível; (e) classificação do mais citado para o menos citado: utilização dos $50 \%$ mais citados; (f) utilização dos 10\% mais recentes.

Os resultados desse estudo evidenciaram que os constructos e subconstructos adotados por Vieira et al. $(2009,2010)$ continuam bastante utilizados nos modelos teórico-conceituais das pesquisas levantadas. No entanto, percebe-se que um número crescente de pesquisas vem incorporando a temática ambiental em pesquisas de colaboração na cadeia de suprimentos (e.g., Bhattacharya et al., 2014; Moreira et al., 2015). Como esse não é o foco específico desta pesquisa, os constructos adotados são considerados válidos pela literatura internacional.

Assim, o modelo de Vieira et al. (2009) são descritos a seguir, conjuntamente com uma revisão da literatura na área. Desta forma, os elementos de colaboração na cadeia de suprimentos estão organizados em elementos estratégicos de colaboração, elementos de integração tática e elementos intagíveis, descritos a seguir:

\subsection{Elementos estratégicos de colaboração}

Trata-se de elementos que busquem criar uma integração de longo prazo (Mehrjerdi, 2009), os quais fazem parte do escopo de qualquer relacionamento sólido. Sodhi \& Son (2009) demonstraram empiricamente que elementos estratégicos possuem grande relevância na performance de uma cadeia dita colaborativa. Na verdade, a literatura científica é deveras rica quando se trata de alianças estratégicas e seu impacto nas cadeias de suprimentos e muitas teorias são utilizadas (Sambasivan et al., 2011; Cao \& Zhang, 2011). A vantagem do modelo adotado está na sua simplicidade, a qual organiza a complexidade dessas teorias priorizando alguns elementos simples. Tais elementos são adotados como constructos pelo presente trabalho, sendo eles:

(i) Compartilhamento de informações de estoque: em um nível estratégico, quando se trata da gestão de operações, o compartilhamento de informações relacionadas aos estoques reais e planejados é crucial, pois trata-se de um elemento de alto impacto nos níveis de serviço aos clientes e no custo das operações, afetando a rentabilidade a longo prazo (Cachon \& Fisher, 2000). Em decisões de planejamento de cadeias colaborativas, o estoque é sempre um elemento relevante para a performance da cadeia, tal como preconizado por modelos como o CPFR (Danese, 2007; Fu \& Piplani, 2004);

(ii) conhecimento das estratégias e dificuldades do parceiro: este constructo é relevante, pois está associado com a capacidade de os parceiros de se conhecerem em um nível estratégico visando obter o que Ryu et al. (2009) chama de strategic fit, que levaria, em uma etapa posterior, a uma confiança maior e, por consequência, a um comprometimento que podem basear uma colaboração efetiva;

(iii) envolvimento da alta gerência: conhecido na literatura como um elemento-chave para a colaboração em cadeias de suprimentos (Roldan et al., 2011; Fawcett et al., 2008), este constructo versa sobre a capacidade da gerência sênior de fornecer condições e dedicar recursos para apoiar a colaboração e a integração na cadeia de suprimentos.

\subsection{Elementos de integração tática}

Em um nível tático, Vieira et al. (2009) defendem, baseados no trabalho de Kanter (1994) e outros, que projetos e atividades conjuntas entre as empresas dependerão da média gerência e da supervisão, promovendo mudanças na organização que conectem as empresas (via melhor troca de informação). Isto inclui composição de equipes, liderança, definição das tarefas e incorporação de rotinas em sistema para troca automática de dados. Para eles, este elemento é formado por:

(i) ações conjuntas: é no nível tático que equipes atuam no desenvolvimento de projetos conjuntos na área logística, no planejamento conjunto de operações e outras ações em parceria que podem ocorrer com as áreas funcionais das empresas envolvidas (Hadaya \& Cassivi, 2007);

(ii) compartilhamento de riscos/ganhos logísticos: trata-se de um assunto que vem atraindo atenção da comunidade em gestão de cadeia de suprimentos (Ceryno et al., 2013; Blos et al., 2009). Vieira et al. (2009) explicam que este tipo de compartilhamento é amplo e pode envolver mesmo elementos como o compartilhamento de custos (e.g., entrega, devolução, causa de 
problemas) e quaisquer ganhos com ações conjuntas (e.g., inovações em produtos e serviços). Tal compartilhamento aumenta as chances de a parceria evoluir positivamente;

(iii) troca de informações logísticas e comerciais: em nível de ações táticas, fala-se em compartilhamento de informações comerciais (e.g., promoções) e logísticas (e.g., planejamento de sortimentos nos canais). Sabe-se que tal compartilhamento em nível tático tem o poder de diminuir a assimetria das informações de operações e promover ganhos importantes de performance (Sodhi \& Son, 2009; Popp, 2000).

\subsection{Elementos intangíveis}

Essa categoria aborda elementos intangíveis (i.e. interpessoais e culturais), formada pelos seguintes constructos:

(i) confiança: é um assunto amplamente estudando na literatura de cadeia de suprimentos (Kwon \& Suh, 2004), pois a confiança tem a capacidade de levar ao comprometimento e à consequente realização de ações conjuntas. Não se trata de um processo unilateral, mas depende de esforços coletivos de todos os membros da parceria (Ramanathan \& Gunasekaran, 2014);

(ii) interdependência: é um subconstructo relacionado à capacidade das empresas de se aproximarem estabelecendo dependência (Vieira et al., 2009; Lusch \& Brown, 1996), criando relações que não são descartáveis, envolvendo coordenação e uma estreita integração de operações, diminuindo assim as chances de os parceiros agirem de forma egoísta (Sambasivan et al., 2011; Clark \& Lee, 2000);

(iii) flexibilidade: refere-se à capacidade de se adaptar às mudanças e de reagir (Thomé et al., 2014). Tal habilidade permite que as relações possam evoluir em meio à diversidade dos parceiros e aos imprevistos que podem ocorrer;

(iv) reciprocidade: significa, para Vieira et al. (2009), "dar e receber em troca". Este subconstructo está relacionado com um elemento-chave para o sucesso das colaborações: o comprometimento. Este, conforme Neumann (2012) e Neumann et al. (2011), está associado à capacidade das empresas em investir na relação de forma recíproca e enviar ao parceiro sinais de envolvimento, base fundamental para que uma relação perdure ou evolua.

O Quadro 1 ilustra os constructos e subconstructos dos elementos de colaboração na cadeia de suprimentos, as referências citadas por Vieira et al. $(2009,2010)$, juntamente com algumas das atualizações das citações obtidas com a revisão sistemática da literatura (listadas na última coluna do Quadro 1).

Para os autores, os elementos estratégicos e os elementos intangíveis formam a base para o processo de colaboração na cadeia de suprimentos. A indissociabilidade desses elementos reforça a colaboração na cadeia de suprimentos, visando desenvolver sinergias entre os parceiros de negócio (Vieira et al., 2010).

O objetivo desta seção foi de apresentar o modelo teórico-conceitual e verificar sua validade perante os avanços recentes na literatura científica. Para uma revisão detalhada da literatura em colaboração em cadeias de suprimentos, o leitor poderá consultar Hudnurkar et al. (2014), Almeida et al. (2015), Zeng et al. (2012) e Charvet \& Cooper (2011). A próxima seção discute como este modelo conceitual foi operacionalizado na presente pesquisa.

\section{Método de pesquisa}

Para atender aos objetivos deste trabalho, foi utilizada principalmente uma abordagem qualitativa de pesquisa. Dentre os diversos tipos de pesquisa qualitativa, o estudo de caso descritivo-exploratório foi considerado o mais adequado para analisar as práticas de colaboração entre a montadora e um fornecedor-chave de primeira camada (Yin, 2003).

Os constructos e subconstructos foram desdobrados em variáveis de pesquisa, mensuradas por meio de questões abertas e aplicadas por meio de um roteiro de entrevista não estruturado. Além das entrevistas, foram utilizados como instrumentos de coleta de dados relatórios enviados à montadora, relatórios do processo de Planejamento de Vendas \& Operações (S\&OP - Sales \& Operations Planning), e observação direta do pesquisador. $\mathrm{O}$ instrumento mais utilizado foi a entrevista, realizada em profundidade com seis pessoas envolvidas diretamente nos processos colaborativos com a montadora. Os entrevistados selecionados atuavam em três níveis hierárquicos (diretoria, gerência e planejamento). A escolha dos participantes se deu baseada em seus perfis, ou seja, selecionaram-se respondentes com cargos pertinentes, em diferentes níveis organizacionais, com experiência e formação adequada para compreender os conceitos e objetivos da pesquisa. A Figura 1 ilustra, a seguir, o perfil dos entrevistados.

O processo de pesquisa foi conduzido em seis meses. Foram realizadas no mínimo 10 reuniões de 30 min com cada um dos entrevistados, totalizando 


\begin{tabular}{|c|c|c|}
\hline \multicolumn{3}{|c|}{$\begin{array}{l}\text { - Graduação em Engenharia Mecânica; } \\
\text { - Pós-Graduação em Administração; } \\
\text { - Há } 17 \text { anos na empresa; } \\
\text { - } 51 \text { anos. }\end{array}$} \\
\hline $\begin{array}{l}\text { Gerên } \\
\text { - Graduação em Engenha } \\
\text { - Especialização em Enge } \\
\text { - Há } 5 \text { anos na empresa; } \\
\text { - } 42 \text { anos. }\end{array}$ & $\begin{array}{l}\text { ábrica A: } \\
\text { Elétrica; } \\
\text { ria de Produção; }\end{array}$ & $\begin{array}{l}\text { Gerência Fábrica B: } \\
\text { - Graduação em } \\
\text { Engenharia Mecânica; } \\
\text { - Há } 9 \text { anos na empresa; } \\
\text { - } 37 \text { anos. }\end{array}$ \\
\hline $\begin{array}{l}\text { Planejamento Itens A1: } \\
\text { - Graduação a concluir } \\
\text { (administração); } \\
\text { - Há } 1 \text { ano na empresa; } \\
\text { - } 24 \text { anos. }\end{array}$ & $\begin{array}{l}\text { Planejamento Itens A2: } \\
\text { - Graduação em } \\
\text { Administração; } \\
\text { - MBA em Gestão de } \\
\text { Operações; } \\
\text { - Há } 4 \text { anos na empresa; } \\
\text { - } 31 \text { anos }\end{array}$ & $\begin{array}{l}\text { Planejamento Itens B1: } \\
\text { - Graduação em Engenharia } \\
\text { de Produção; } \\
\text { - Há } 5 \text { anos na empresa; } \\
\text { - } 29 \text { anos. }\end{array}$ \\
\hline
\end{tabular}

Figura 1. Perfil dos entrevistados. Fonte: Dados da pesquisa.

mais de 30 encontros, ao todo. Isso permitiu melhor triangulação dos dados levantados. As entrevistas foram gravadas com a autorização dos entrevistados e depois transcritas. Os relatórios com as transcrições foram entregues individualmente a cada entrevistado a fim de validar ou retirar algum trecho que não conviesse ser publicado pelos autores. A análise dos dados foi realizada segundo a experiência empírica do pesquisador, respaldada pela literatura citada no modelo teórico-conceitual adotado. A partir da análise dos dados foi produzida uma narrativa geral do caso descrita na seção a seguir.

\section{Descrição e discussão do caso}

\subsection{Caracterização da empresa e do segmento de mercado em que atua}

O objeto de estudo, uma fabricante de autopartes, é a maior empresa em seu setor na América Latina. Com o capital aberto e $100 \%$ nacional, a empresa é fornecedora de produtos para as principais montadoras no país e do exterior. Conta com mais de 1.000 colaboradores e ocupa uma área de mais de $15.000 \mathrm{~m}^{2}$, dividida em dois parques fabris, situados na mesma região. Cada planta industrial produz diferentes componentes, contando com uma capacidade industrial instalada de mais de 3.000 .000 de unidades por ano.

A empresa atua em dois segmentos distintos no mercado. O primeiro deles é o OEM (Original
Equipment Manufacturer), que se destina a fornecer sistemas para as grandes montadoras. $\mathrm{O}$ segundo segmento é o Aftermarket, que atende ao mercado de reposição de peças. O primeiro segmento representa $80 \%$ do faturamento desta empresa, enquanto o segundo representa apenas $20 \%$. Estes segmentos de atuação da empresa possuem características muito distintas.

O mercado OEM, por exemplo, é voltado para o fornecimento de peças originais para as montadoras, estando sujeito às suas especificações, descritas em complexos contratos. Tais contratos possuem muitas cláusulas que estipulam acordos e exigências, incluindo prazo de entregas, qualidade, exclusividade de projeto, além das multas por infração de algumas das exigências, bem como por quebra de contrato por ambas as partes. $\mathrm{O}$ atendimento às montadoras exige maior atenção para com diversos aspectos relacionados com a engenharia do negócio, incluindo desenvolvimento de produtos, eficiência operacional na utilização de ativos, custos, produtividade, entre outros. Isto ocorre, pois, a parceria com as montadoras prevê o desenvolvimento conjunto dos produtos, exclusividade de compras e os preços previamente estipulados. Dessa forma, os contratos firmados garantem uma relativa estabilidade com relação àquele cliente, principalmente pela adoção do sistema de remessa, em que a montadora se compromete a enviar mensalmente sua previsão de vendas (denominado, neste trabalho, de forecast). 
Além do mais, a empresa fornecedora se compromete a entregar exatamente o que a montadora havia previsto, sem a necessidade de emissões de ordens de compra. Para tanto, não há necessidade de grandes ações de marketing e vendas, mas sim o cumprimento das exigências do cliente. Assim, os ganhos da empresa estudada se concentram mais na redução de seus custos, pois há pouca flexibilidade na busca por melhores preços, devido ao poder de negociação das montadoras.

Uma característica fundamental do segmento OEM é a maneira como a demanda do mercado é percebida e trabalhada no planejamento de vendas e operações (S\&OP). Neste caso, as montadoras enviam aos fornecedores seu forecast de vendas, via EDI (Electronic Data Interchange), para um horizonte de doze meses agregado, geralmente, mês a mês. No entanto, no mês vigente, é enviada aos fornecedores uma confirmação para aquele mês com divisão semanal. Constantemente são identificadas grandes variações entre os forecasts enviados.

Já o segmento Aftermarket é voltado para o atendimento do mercado de peças de reposição. Neste caso, o negócio é mais dinâmico que no segmento de OEM, uma vez que a lógica seguida é do mercado Spot e não contratual. Neste caso, não há poucos clientes de alta representatividade, mas sim muitos pequenos clientes dispersos que compram pequenos volumes e buscam baixos preços. Assim, no dia a dia, o negócio se concentra em superar as metas de vendas estabelecidas por meio da retenção dos clientes já existentes e da conquista de outros novos clientes, já que a concorrência é mais evidente e mais agressiva. Esse mercado é mais sensível a promoções, pacotes de serviços, disponibilidade de produtos e rapidez de entrega. Diferentemente do segmento OEM, não existem contratos com programas de remessas, em que se acorda uma quantidade pré-definida de produtos para um horizonte fixo. As vendas são realizadas dia a dia, e a busca por clientes é intensa.

As principais diferenças entre os segmentos OEM e Aftermarket, observadas na empresa estudada, estão representadas no Quadro 2 a seguir.

O Estudo de caso realizado trata especificamente do segmento OEM, dada a complexidade de seu planejamento, a sua representatividade econômica no negócio como um todo, bem como sua natureza colaborativa fornecedor-montadora; diferente do Aftermarket que segue uma lógica de mercado Spot.

Analisando o negócio em que a empresa se encontra, o segmento OEM está inserido na representação da tradicional estrutura de uma cadeia de suprimentos, em que a montadora constitui a empresa foco, e a empresa estudada representa um fornecedor de primeira camada.

\subsection{Colaboração entre o fornecedor-chave e a montadora}

Esta seção está estruturada de forma a apresentar as respostas de cada um dos entrevistados, de acordo com o modelo teórico-conceitual.

\subsubsection{Concepção do conceito de colaboração}

Antes de entrar no modelo teórico-conceitual propriamente dito, a primeira parte da entrevista buscou identificar o grau de compreensão e maturidade dos entrevistados sobre o tema colaboração na cadeia de suprimentos.

Quadro 2. Diferenças básicas entre os mercados de OEM e Aftermarket.

\begin{tabular}{|l|l|l|}
\hline \multicolumn{1}{|c|}{ Características } & \multicolumn{1}{|c|}{ OEM } & \multicolumn{1}{c|}{ Aftermark } \\
\hline Natureza do Negócio & Business to Business & Business to Business e Business to Consumer \\
\hline Clientes & Montadoras & $\begin{array}{l}\text { Canais de vendas: Oficinas Mecânicas, Postos de } \\
\text { Serviços Autorizados, Distribuidores, Concessionárias, } \\
\text { Mercado Internacional e Pessoas Físicas }\end{array}$ \\
\hline Previsão de Demanda & $\begin{array}{l}\text { Montadoras enviam mensalmente } \\
\text { seu forecast de vendas para os } \\
\text { próximos 12 meses }\end{array}$ & $\begin{array}{l}\text { Análise do mercado de venda de carros usados, } \\
\text { histórico dos clientes, vida útil das direções } \\
\text { originais, entre outros }\end{array}$ \\
\hline Portfólio & $\begin{array}{l}\text { Específico para cada montadora } \\
\text { e modelo de veículo, dentro da } \\
\text { gama de possibilidades do mix } \\
\text { de produtos e da capacidade da } \\
\text { empresa }\end{array}$ & $\begin{array}{l}\text { Todos os produtos produzidos pela empresa para } \\
\text { montadoras, além de kits de reparo exclusivos } \\
\text { para esse segmento, kits para alteração de sistema } \\
\text { mecânico para hidráulico e assistência técnica }\end{array}$ \\
\hline Vendas & Sistemas de remessa & $\begin{array}{l}\text { Equipe de vendas com metas específicas para cada } \\
\text { canal }\end{array}$ \\
\hline Unidade de Negócios & Próprio parque fabril & $\begin{array}{l}\text { Situado dentro do parque fabril, apesar de contar } \\
\text { com uma estrutura própria }\end{array}$ \\
\hline
\end{tabular}

Fonte: Proposto pelos autores. 
Pôde-se observar que, quanto mais alto na hierarquia da empresa, mais clara era a percepção sobre a real dimensão da colaboração por parte dos entrevistados. Apesar de o conceito de colaboração em cadeia de suprimentos não estar completamente maduro para todos os entrevistados, a diretoria possui uma boa concepção dele, tal como demonstrado na fala do Diretor:

[...] o relacionamento colaborativo é uma questão estratégica, em que as empresas que optam por estabelecer esse tipo de relacionamento devem estar pautadas no ganho mútuo, e na satisfação dos clientes finais da cadeia. Contudo, é necessário que essas empresas estejam preparadas para a colaboração, pois não basta somente a "boa vontade" de pensar no elo seguinte da cadeia, a empresa deve ter seus processos internos estruturados e maduros, para que as vantagens de um relacionamento colaborativo apareçam e não se torne mais uma prática sem função dentro da empresa.

O Diretor entrevistado completou mencionando que a

colaboração começa com a troca de informações operacionais e, à medida que o grau de confiança vai aumentando, a tendência é que se compartilhem informações estratégicas e tomem ações em conjunto.

No nível tático, a percepção de colaboração é mais concreta. Segundo os gerentes entrevistados, o relacionamento colaborativo está pautado basicamente no estabelecimento de parcerias, em que um elo somente "dará um passo", se perceber que o outro também o fará. Isso está muito relacionado ao conceito de "commitment", defendido por Neumann (2012) e Neumann et al. (2011) como um elemento fundamental visando reduzir os riscos de falência da relação colaborativa. No entanto, entre os parceiros estudados ainda persiste a desconfiança de que dados compartilhados poderão ser utilizados pelos clientes, de forma a fortalecer a concorrência, ou ainda para barganhar melhores preços e condições de pagamento. Contudo, apesar de todas as desconfianças, um dos gerentes entrevistados acredita que a colaboração é o "futuro das companhias".

Finalmente, no nível operacional, acredita-se que o relacionamento colaborativo é resultado de maior proximidade entre as partes, em que um influencia as operações do outro, de forma a ajudar na rotina de trabalho e garantir melhores desempenhos para todos os envolvidos. O planejador acredita que o relacionamento colaborativo é fruto de negociações, em que empresas se unem para vencer concorrentes.

Mediante as percepções sobre colaboração coletadas, pode-se inferir que, na empresa estudada, quanto mais alto o cargo ocupado, maior é a percepção sistêmica do que pode vir a ser um verdadeiro relacionamento colaborativo. É evidente que, quanto mais operacional é a função do entrevistado, mais o conceito de relacionamento colaborativo se aproxima da realidade de trabalho deles, pautado em desconfianças e, muitas vezes, em conceitos rasos. Apesar disso, é importante ressaltar que, mesmo de maneira incompleta, o conceito está internalizado em todos os entrevistados

Além do mais, pode-se dizer que, de forma geral, as percepções e entendimentos dos entrevistados sobre o conceito de colaboração são coerentes com as definições teóricas da literatura. É interessante destacar que são capazes de identificar vantagens no processo de colaboração. Porém, infelizmente não se evidenciaram todos os ganhos potenciais ao se adotar essa estratégia. A visão do Diretor é a que mais se aproxima das potencialidades do relacionamento colaborativo. Este lembrou, de maneira pertinente, a necessidade de a empresa estar estruturada por processos de negócios, de forma madura e organizada, para que possa assim trabalhar de forma integrada e colaborativa com outro elo da cadeia, como corroboram Bowersox et al. (2014) e Corrêa (2010).

Com o conceito de colaboração em mente, os entrevistados passaram a discutir as ações colaborativas de acordo com o modelo teórico-conceitual, organizado em elementos estratégicos, táticos e intangíveis, tal como discutido a seguir.

\subsubsection{Elementos estratégicos}

\subsubsection{Compartilhamento de informações de estoque}

Para clássicos da literatura, como Mentzer et al. (2001), a adoção do relacionamento colaborativo prevê o compartilhamento de informações, tais como: níveis de estoques, forecasts, promoções de vendas e estratégias de marketing. Isto permite a redução da incerteza entre os elos da cadeia e resulta em melhores performances. Nesse mesmo sentido, Cooper et al. (1997) ainda completam afirmando que a colaboração não pode ser limitada às necessidades momentâneas e devem ocorrer nos mais diversos níveis da empresa (do operacional ao estratégico), envolvendo coordenação cross-funcional entre os membros da cadeia de suprimentos.

Para os entrevistados, a base da gestão da informação na empresa se dá por meio de um ERP (Enterprise Resource Planning) da SAP (SAP ECC), o qual é o sistema integrado mais comum nas empresas do setor. A implementação deste sistema se deu há aproximadamente dois anos. Antes da sua implementação, a empresa contava com um ERP diferente e vários outros sistemas legados.

Além do SAP ECC, a empresa faz uso do software SINTEL, responsável por receber e decodificar o EDI contendo o forecast de vendas, enviado pela 
montadora. Este software era integrado ao SAP, de modo que o EDI recebido fosse diretamente carregado no módulo de planejamento da produção do SAP. Essa demanda era considerada como oficial para os produtos em questão, sem que ao menos se fizesse uma análise prévia das variações de demanda. Confirmado pelos entrevistados, a empresa não contava com nenhuma outra ferramenta de resposta rápida. Muitas delas eram até desconhecidas pelos entrevistados. Esse comportamento pode, de certa forma, ser explicado pelo fato de a maior parte das práticas colaborativas (Continuous Replenishment - CR, Vendor Managed Inventory - VMI, Efficient Consumer Response-ECR, Collaborative Planning, Forecasting, and Replenishment - CPFR, etc.) na cadeia de suprimentos ocorrerem a jusante da cadeia, envolvendo fabricantes e grandes redes varejistas. Poucos são os estudos que analisam profundamente as práticas colaborativas a montante na cadeia de suprimentos (Badenhorst, 2010; Fu \& Piplani, 2004; Grackin, 2014; Kersten \& Stengel, 2011; McClellan, 2001). Isso é especialmente verdadeiro na indústria automobilística brasileira (Munhoz \& Vieira, 2009; Rodrigues \& Sellitto, 2008).

A utilização do software de recebimento e decodificação do EDI é de fundamental importância, no que diz respeito ao processo adotado para a realização de pedidos, feito por divisão de remessas. Segundo os entrevistados, a previsão de vendas (i.e., o forecast) da montadora representa sua demanda de produtos fornecidos e esta representa exatamente a quantidade que a empresa fornecedora deverá disponibilizar à montadora na data acordada. Esse modelo de divisão de remessas evitava a burocracia do envio de pedidos a cada período.

As coordenadas desse modelo de pedido eram definidas nos contratos assinados por ambas as partes, o que levava a uma baixa flexibilidade de negociação, pois eles eram extremamente detalhados, descrevendo todas as situações possíveis e prevendo multas consideravelmente altas por qualquer desvio do acordado. Assim, até que o contrato atingisse o vencimento, o acordo persistia da forma como foi documentado. Segundo os entrevistados, havia poucas possibilidades de mudanças, a não ser em situações emergenciais, o que poderia também incorrer em pesadas multas.

Em relação ao constructo compartilhamento de informações de estoques, foi basicamente indagado se havia conhecimento dos níveis destes nos clientes e vice-versa. Todos os entrevistados responderam convictos e de forma unânime que não havia compartilhamento dos níveis de estoque nas montadoras. Contudo, o Gerente da Fábrica A complementou dizendo que não acredita que essa informação seja um dia compartilhada entre os elos, pois os níveis de estoque eram considerados como informações altamente estratégicas para a empresa, que poderia se utilizar dessa alternativa para buscar melhores preços, negociar volumes de compras distintos ou favorecer um ou outro cliente.

A visão destacada anteriormente retrata um ambiente extremamente favorável para que o efeito chicote ocorresse nesta cadeia. Observou-se na empresa uma baixa coordenação interna, que não transmitia confiança ao elo ou processo seguinte quanto aos prazos e às quantidades demandadas; dessa forma, o pedido (EDI) enviando pela montadora não retratava a realidade da demanda percebida por ela.

Conforme abordado por Corrêa (2010), Handfield $\&$ Nichols (2002) e Simchi-Levi et al. (2010), entre outros autores, um dos motivos para a ocorrência do efeito chicote é justamente o caso em questão. Desta forma, na tentativa de ter sua demanda atendida, a montadora acabava pedindo uma quantidade maior que a necessária, para estocar ou para receber parte do pedido (caso o fornecedor não tivesse capacidade para atender $100 \%$ do pedido). Essa postura levava a uma falsa constatação de demanda crescente ou altamente variável ao longo da cadeia, quando na verdade ela não era a demanda real.

Esse comportamento garantia que a montadora obtivesse o produto necessário em estoque, contudo o stress gerado devido à flutuação da demanda era extremamente alto. Isto pois, se em um mês a montadora acumulava muito estoque, no mês seguinte o pedido era menor, deixando a falsa impressão de que a demanda diminuía, podendo levar a empresa fornecedora a desacelerar sua produção, quando na verdade a demanda do mercado poderia ter sido estável, ou até mesmo maior. E se, por ventura, no mês após essa desaceleração o pedido da montadora voltasse a ser inflado, a empresa fornecedora poderia não ter capacidade para atender a essa variação, gerando mais stress, mais desconfiança, reiniciando o ciclo do efeito chicote. O não compartilhamento dos níveis de estoque era percebido com uma "carta na manga", quando na verdade era uma das causas de tantos problemas.

Esse efeito percebido na cadeia era uma das maiores causas de reclamações entre os entrevistados, que conseguiam identificar precisamente todos os efeitos resultantes dessa baixa coordenação.

\subsubsection{Conhecimento do parceiro}

Com relação ao compartilhamento além do forecast que visasse a criação de um conhecimento mútuo entre os parceiros, o Diretor afirmou que até o momento não existia nenhuma iniciativa nesse sentido. O que se praticava era, em regra geral, a divulgação (por parte do fornecedor) dos 
demonstrativos financeiros, em caráter obrigatório, devido ao fato de a empresa ser de capital aberto. Contudo, não havia um direcionamento desses dados. Eles eram disponibilizados no portal institucional da empresa. O Diretor ainda completou enfatizando que:

[...] indicadores internos (operacionais) tais como qualidade, produtividade, não são divulgados, pois são confidenciais. No entanto, ao se firmar um contrato com alguma montadora há de se comprovar capacidade, indices de defeitos, entre outros números [...] mas no dia a dia, essas informações não são repassadas, a menos que seja uma exigência da montadora, o que às vezes acontece.

Em relação ao envio de informações por parte da montadora, o diretor acrescentou: "a recíproca também é verdadeira, em se tratando de dados que chegam até nós; o cliente é uma caixa fechada, o que recebemos é apenas o EDI (forecast de vendas)". A visão da gerência e dos planejadores não diferiu do exposto pelo diretor entrevistado.

Com relação ao compartilhamento das metas do negócio, os planejadores, em geral, não souberam responder, uma vez que se tratava de uma questão de cunho estratégico para a empresa. Já os gerentes divergiram em relação a essa questão. Um deles citou a divulgação do mapa estratégico (alusão ao balanced score card) da empresa como sendo um compartilhamento de metas, mesmo que macro. Para o outro gerente, não havia compartilhamento, nem a montante, nem a jusante na cadeia.

\subsubsection{Envolvimento da alta gerência}

Finalmente, o último constructo estratégico versa sobre o envolvimento da alta gerência, a qual deve agir conjuntamente visando fornecer condições (e.g., recursos) para favorecer a colaboração e integração entre as empresas.

Os entrevistados demonstraram que, mesmo que haja uma crença por parte da direção de que a colaboração tem o potencial de trazer grandes benefícios, poucas são as ações apoiadas pela alta gerência visando a evolução da colaboração. Inicialmente, recursos foram dedicados à colaboração, como na implantação de infraestrutura de tecnologia EDI, por exemplo. No entanto, essas ações não evoluíram no tempo e se limitam, basicamente, a ações do tipo transacionais.

Além disso, as entrevistas deixaram evidente que há falta de envolvimento conjunto das altas gerências no sentido de sincronizar as operações de fabricação, com as ações de marketing e vendas. Isto causa prejuízos claros ao fornecedor, o qual é obrigado a mudar seus planos de fabricação, suprimentos e distribuição de forma custosa.

\subsubsection{Elementos táticos}

\subsubsection{Ações Conjuntas \& Troca de Informações Logísticas e Comerciais}

Ao serem questionados sobre ações conjuntas, praticamente todos os respondentes demoraram para responder, pois ficaram pensativos a fim de resgatar na memória alguma ação conjunta. Isso talvez evidencie que as práticas colaborativas não eram tão comuns e evidentes.

Este constructo abordou questões como planejamento conjunto de promoções, compartilhamento do volume de vendas realizadas, lançamento de novos produtos em parceria, entre outros aspectos relacionados ao assunto. Decisões tomadas em conjunto envolvem diversos fatores relacionados à confiança e à interdependência, uma vez que um elo se apoia em outro, para que juntos alcancem um ganho maior, do que individualmente, como relata Lambert (2006).

Uma vez que os planejadores não participavam de fóruns destinados ao estabelecimento de alianças estratégicas, essa pergunta não foi considerada pertinente a eles. Os gerentes, apesar do baixo envolvimento em questões estratégicas, afirmavam com veemência que a empresa e a montadora não tomavam decisões em conjunto, a não ser no desenvolvimento de novos produtos. Isso ocorria porque era de fundamental interesse, por parte da montadora, o desenvolvimento de projetos dedicados aos seus próprios lançamentos. Contudo, segundo os entrevistados, não se pode afirmar que as decisões eram tomadas conjuntamente na totalidade do tempo, pois, em muitas situações, a montadora exigia certos requisitos, colaborando apenas na engenharia do produto propriamente dita. Era comum a montadora alocar alguns projetistas e engenheiros para trabalhar em conjunto com a equipe de desenvolvimento da empresa fornecedora, nos moldes da prática conhecida na literatura como ESI (Early Supplier Involvement) (Schiele, 2010). Esse tipo de ação conjunta ocorria frequentemente quando a montadora previa o lançamento de um novo carro no mercado, com um novo produto a ser desenvolvido.

Apesar de colaborarem no desenvolvimento de um produto específico, não se pode afirmar que outras decisões eram tomadas conjuntamente. Um exemplo disso, conforme enaltecido anteriormente, refere-se apenas ao repasse da previsão de vendas. Segundo os entrevistados, não existia um processo de decisão colaborativo entre a montadora e a empresa para tratar de exceções nos planos de produção do fornecedor e nos planos de abastecimento da montadora.

O Diretor entrevistado ressaltou que era recorrente o fato de a montadora lançar uma promoção na mídia, e a empresa somente tomar conhecimento por meio de propagandas na televisão, ou qualquer outro meio de divulgação. Ele completou mencionando que: 
[...] normalmente a montadora se prepara com estoques de segurança durante algum tempo para lançar certas promoções, ou certos produtos. No entanto, a falta de informação para nós faz com que, em muitos casos falte produto no mercado. Ou até mesmo, quando sabemos que a montadora lançará um novo carro, não é clara a data em que isto será realizado, impedindo assim que nos preparemos para um verdadeiro boom no consumo. O meio encontrado por nós é acompanhar sempre as notícias do setor, bem como o comportamento da economia, para tentar prever estatisticamente a demanda que virá em um futuro breve.

Esse relato remete novamente à distorção da demanda transmitida ao longo da cadeia, provocando o efeito chicote e stress entre os elos, fazendo com que o fornecedor trabalhe sem a informação real e concreta sobre os fatos, e fique à mercê da estratégia de compras da montadora.

\subsubsection{Compartilhamento de riscos/ganhos}

Todas as entrevistas indicaram que não há uma política de compartilhamento de ganhos, perdas e riscos. Este constructo explorou um dos aspectos mais importantes da colaboração na cadeia de suprimentos, pois somente empresas com alto grau de confiança em relação aos seus clientes e fornecedores mantêm um relacionamento colaborativo profundo e de longo prazo (Mentzer et al., 2001) que envolva o compartilhamento de perdas e ganhos. Este tipo de compartilhamento é uma garantia que ambas as partes podem obter, pois a relação do tipo "ganha - ganha" pode amenizar, por exemplo, uma perda que um elo poder sofrer, minimizando os efeitos.

Apesar de todos os benefícios dessa prática, os entrevistados foram claros ao responder essa pergunta, pois não havia nenhuma evidência de compartilhamento de ganhos, perdas, riscos ou custos. Um dos planejadores mencionou, por exemplo, que "é cada um por si", ou seja, não existia nem ao menos um indicativo de que o compartilhamento ocorresse.

\subsubsection{Elementos intangíveis: confiança, interdependência, flexibilidade e reciprocidade}

Este constructo abordou o desenvolvimento de relações mais próximas entre os elos da cadeia em questão, no que diz respeito ao conhecimento dos limites uns dos outros e às práticas de crescimento conjunto.

Essa questão foi mais direcionada ao Diretor entrevistado, uma vez que este possuía mais propriedade sobre $o$ assunto. Ele reconheceu que algumas iniciativas no sentindo de aproximar a montadora e a empresa ocorriam durante as constantes visitas realizadas pelas montadoras nos fornecedores e vice-versa.

Segundo o Diretor, as visitas eram sempre muito comentadas na fábrica, alterando a rotina de todos os trabalhadores, pois muitos se dedicavam a acompanhar os visitantes via participação de workshops. Para o Diretor, era inegável que durante essas visitas muitas experiências fossem compartilhadas. Contudo, destacou o clima de tensão que se instaurava na empresa, nas vésperas de alguma visita. Isso porque, muitas vezes a impressão transmitida era muito mais de inspeção, do que de desenvolvimento conjunto. O Diretor complementou que:

\section{[...] não se pode negar que exista alguma iniciativa no sentido de conhecer nosso trabalho. A recíproca nem sempre é verdadeira. As visitas às montadoras são menos frequentes e mais restritas, devido aos segredos de fábrica existentes [...] e as visitas das montadoras nas nossas plantas são acordadas no momento de se estabelecer as cláusulas dos contratos, ou seja, existe uma obrigatoriedade em se apresentar as instalações e os números do negócio para o cliente.}

Outras iniciativas citadas pelo Diretor eram as cerimônias de premiações, em que os fornecedores recebiam prêmios e reconhecimento por algumas conquistas, estando relacionadas ao desempenho operacional em qualidade, custo, entre outros indicadores. Para o Diretor entrevistado, esse tipo de iniciativa estimulava os fornecedores a cada vez se aperfeiçoarem mais. Em alguns casos, cursos e treinamentos "on the job" eram oferecidos pelas próprias montadoras, a fim de gerar ganhos para ambas as partes.

Apesar destas iniciativas, pode-se concluir que os principais elementos deste constructo (confiança, interdependência, flexibilidade e reciprocidade) ainda são restritos. Isso se dá, pois há pouca confiança, já que as trocas são basicamente unidirecionais. Conforme mencionado anteriormente, entre os parceiros ainda persiste a desconfiança de que dados compartilhados poderão ser utilizados pelos clientes para barganhar melhores preços e condições de pagamento, por exemplo. Quanto à interdependência, há fortes indícios de que ela seja mediana, pois a montadora pode reagir de forma egoísta quando do envio de seus forecasts. Além disso, há pouca flexibilidade, já que a relação é amarrada por um contrato amplamente detalhado, descrevendo todas as situações possíveis e prevendo multas consideravelmente altas por qualquer desvio do acordado. Finalmente, com relação à reciprocidade, pode-se dizer que esta também é limitada, pois o fornecedor absorve de forma isolada os problemas de variação da demanda da montadora, sem que a montadora tome conhecimento das dificuldades vividas por eles. Conforme explicado, o stress produzido 
devido à flutuação da demanda era extremamente alto, o qual gerava mais desconfiança, reiniciando o ciclo vicioso do efeito chicote.

\subsubsection{Discussão}

Dentre todas as colocações dos entrevistados e observações realizadas, pode-se elencar algumas passagens importantes para a identificação dos propósitos deste trabalho.

Primeiramente, com relação ao nível de conhecimento sobre colaboração na cadeia de suprimentos, pode-se inferir que este era satisfatório, visto que os principais aspectos da colaboração são apontados por eles, especialmente no nível estratégico. No entanto, percebe-se, de maneira geral, um fenômeno de dualidade: por um lado, há comportamento proativo que visa reforçar o relacionamento colaborativo entre o fornecedor-chave e a montadora e os benefícios que possam resultar dessa interação; por outro lado, constata-se uma postura receosa à colaboração, por temer a perda de competividade via compartilhamento de informações consideradas pelos entrevistados como estratégicas.

Diante desse fato, observa-se uma colaboração num nível mais operacional, evidenciada, por exemplo, pelo uso do EDI. No entanto, o próprio uso desta prática de integração revela que o processo de colaboração entre tais agentes não atingiu sua maturidade. Em processos colaborativos entre fabricantes de bens de consumo e grandes redes varejistas, observa-se que o uso do EDI é uma das primeiras práticas colaborativas na cadeia de suprimentos (Gunasekaran \& Ngai, 2004). Entretanto, o uso do EDI mostra-se limitado em ambientes complexos e dinâmicos, que necessitam de maior maturidade e agilidade na gestão do relacionamento entre os agentes na cadeia de suprimentos.

A evolução natural do uso do EDI deve caminhar para a incorporação de práticas que gerenciam o processo colaborativo de forma a minimizar as rupturas de estoque. Para tanto, observa-se, em processos colaborativos no varejo, a incorporação de práticas como CR, VMI, ECR e CPFR, que visam, principalmente este último, maior estabilidade do sistema como um todo, ao administrar de forma proativa e colaborativa as restrições ou exceções na gestão da demanda no âmbito da cadeia. Para tanto, o CPFR é citado pela literatura como uma das principais práticas de gestão da demanda entre fabricantes de bens de consumo e grandes redes varejistas (Ramanathan \& Gunasekaran, 2014; Danese, 2007).

Assim, mediante as entrevistas e observações realizadas, pode-se inferir que, no caso estudado, o processo de colaboração na gestão do abastecimento apresenta baixa maturidade, limitada à utilização do EDI, bem como pela inexistência de um processo formal de gestão colaborativa do abastecimento de itens da montadora (inspirado do CPFR, por exemplo).

Além do mais, notou-se que um input vital para o sucesso da gestão colaborativa, a confiança, é limitado no presente caso. Isto que evidencia um comportamento de uma relação ganha-perde, em vez da relação ganha-ganha, preconizada como um dos paradigmas da gestão estratégica de uma cadeia de suprimentos. Talvez esse fato possa ser explicado pela forma de governança exercida pela montadora sobre os fornecedores, que assumem um papel muito mais passivo que proativo na gestão colaborativa do processo de abastecimento. Outra ocorrência que se mostrou negativa na consolidação de um relacionamento colaborativo está relacionada ao fato de o fornecedor-chave apresentar problemas de integração de processos. Observou-se que a existência de processos internos desordenados e conflituosos ocasionou muitas falhas no suprimento de itens para a montadora.

De maneira idiossincrática, para se proteger de rupturas e incertezas, a montadora exercia cada vez mais uma governança autoritária, formalizando via acordos contratuais bem regimentados sobre o abastecimento contínuo de seus processos, diminuindo assim o poder de barganha desse fornecedor na gestão de exceções e restrições de fornecimento. Por outro lado, como observado pelo diretor, o fornecedor possui baixa maturidade na integração de processos de negócios internos à empresa. Essa situação pode ter contribuído para a geração de uma espiral crescente de engessamento do relacionamento colaborativo com montadora. Esta, por desconfiança, restringia o acesso do fornecedor aos níveis de estoque nos pontos de venda. Outras ações de proteção tomadas pelas montadoras (pedidos inflados e manutenção de estoques estratégicos) potencializavam o efeito chicote, causando grandes flutuações de demanda e estoques ao longo da cadeia.

Além da utilização do EDI, é possível destacar outras medidas no sentido de firmar um relacionamento colaborativo entre a montadora e o fornecedor-chave pesquisado, embora incipiente. Dentre elas, é importante destacar: o desenvolvimento conjunto de novos produtos (embora os entrevistados não reconheçam isso como uma prática colaborativa), que demonstrou a interdependência entre os elos; as constantes visitas de representantes da montadora no fornecedor, mesmo em "clima de inspeção", proporcionaram, na visão dos entrevistados, a oportunidade de conhecimento mútuo.

Neste caso, pode-se concluir, para o caso analisado, que o primeiro passo em busca do estabelecimento de um relacionamento colaborativo já foi dado, mas existem muitas barreiras a serem ultrapassadas, sendo, uma delas, a coordenação dos processos internos da 
Quadro 3. Resumo dos elementos de colaboração entre o fornecedor e a montadora.

\begin{tabular}{|c|c|c|}
\hline Constructos & Itens & Avaliação \\
\hline \multirow{6}{*}{$\begin{array}{l}\text { Elementos de } \\
\text { Colaboração } \\
\text { Estratégicos }\end{array}$} & Compartilhamento de informações de estoque & $\downarrow$ \\
\hline & Compartilhamento de informações sobre promoções e estratégias de marketing & $\downarrow$ \\
\hline & Conhecimento das dificuldades do parceiro & $\searrow$ \\
\hline & Envolvimento da alta gerência & $\nearrow$ \\
\hline & Utilização de tecnologia de informação para compartilhamento de informações (EDI) & $\searrow$ \\
\hline & Utilização ou conhecimentos de programas de resposta rápida utilizados & $\downarrow$ \\
\hline \multirow{5}{*}{$\begin{array}{l}\text { Elementos de } \\
\text { Colaboração } \\
\text { Táticos }\end{array}$} & Ações e Decisões conjuntas & $\searrow$ \\
\hline & Compartilhamento de riscos e ganhos & $\searrow$ \\
\hline & Compartilhamento de metas de negócio (mapa estratégico) & $\searrow$ \\
\hline & Compartilhamento de previsões de vendas da montadora para o fornecedor & $\uparrow$ \\
\hline & Integração de processos internos & $\searrow$ \\
\hline \multirow{3}{*}{$\begin{array}{l}\text { Elementos } \\
\text { interpessoais, } \\
\text { culturais e } \\
\text { intangíveis }\end{array}$} & Confiança & $\downarrow$ \\
\hline & Interdependência e Reciprocidade & $\searrow$ \\
\hline & Flexibilidade nas negociações & $\downarrow$ \\
\hline
\end{tabular}

Legenda: $(\uparrow)$ alto; $(\downarrow)$ baixo; $(\nearrow)$ em crescimento; $(\searrow)$ em declínio. Fonte: Dados da pesquisa.

empresa, o que pode garantir e transmitir confiança aos seus clientes.

É importante lembrar que a montadoras (no mundo e especialmente no Brasil) foram pioneiras na experimentação de conceitos radicais e inovadores de colaboração na cadeia de suprimentos. Desde os anos 1990, empresas como VW e Audi realizaram experimentos importantes, como o consórcio modular em Resende (Pires, 1998) e o caso do condomínio modular em São José dos Pinhais (Sacomano et al., 2013; Vanalle \& Salles, 2011). No entanto, o setor industrial apresenta indicativos de que o conceito de colaboração ainda está longe de ser maduro e avançado, mesmo em um caso envolvendo uma grande montadora e um fornecedor-chave de primeira camada, considerados empresas de classe mundial, como as empresas aqui estudadas.

O Quadro 3 resume os elementos de colaboração entre o fornecedor e a montadora, de acordo com o quadro teórico-conceitual adotado no presente trabalho.

\section{Conclusão}

Este trabalho objetivou compreender o nível de colaboração no relacionamento de uma indústria fornecedora de autopeças com a montadora. O setor automobilístico vem sendo alvo de constantes pesquisas no âmbito da gestão de serviços e operações, devido à sua grande importância no cenário socioeconômico brasileiro e mundial, bem como devido às transformações que o setor vem passando desde a década de 1990, principalmente com relação a novas estratégias de gestão da cadeia de suprimentos. Neste sentido, a integração com os elos a montante, principalmente os de primeira camada, é uma prática já estabelecida na área há anos. Assim, as montadoras vêm adotando diversas práticas colaborativas, com destaque para o envio de forecasts de vendas para seus fornecedores via EDI, a fim de obter a quantidade de produtos necessários, de acordo com sua demanda.

No entanto, essa relação ainda não é totalmente compreendida pela literatura, mesmo sendo este um assunto estudado há mais de uma década. Em se tratando de grandes montadoras e fornecedores importantes de primeira camada, espera-se um grau de maturidade elevado nas relações colaborativas entre esses dois elos importantes da cadeia.

O presente estudo de caso evidenciou que as relações colaborativas são ainda insipientes e prevalece a relação tradicional fornecedor-cliente e não de parceiros altamente integrados, trabalhando juntos para melhorar a cadeia como um todo.

A colaboração é perceptível em alguns momentos, como nas visitas constantes do cliente no fornecedor $\mathrm{e}$ vice-versa, no desenvolvimento em parceria de novos produtos, entre outras práticas menores. A prática de maior impacto na gestão das operações do fornecedor refere-se ao envio de informações de forecast de vendas ao fornecedor via EDI. No entanto, cabe notar que, apesar de ser nomeado forecast, a maior parte das informações tem as características de pedidos e não de previsões de vendas em si. Fora a primeira informação anual de forecast (essa sim uma previsão anual), os forecasts mensais assemelham-se, na verdade, a ordens de compras enviadas eletronicamente. Além disso, essa informação enviada nem sempre é confiável, pois ela é altamente volátil ao longo do tempo, ocasionando inúmeros efeitos negativos na cadeia como um todo, dentre eles o efeito chicote. Nesse sentido, uma das propostas de diversos autores (e.g., Simchi-Levi et al. (2010) e outros) para a redução do efeito chicote é a adoção de práticas colaborativas que inclui a troca de informações reais de demanda 
entre os elos da cadeia. No entanto, essa não faz parte do caso estudado.

Em suma, pôde-se concluir que existe um relacionamento colaborativo entre fornecedor e montadora, embora muito incipiente. As evidências encontradas dizem respeito às práticas primárias de colaboração, indicando o início do estabelecimento de um relacionamento colaborativo. Essas iniciativas são insuficientes para reduzir o nível de incerteza na cadeia, pois, de forma isolada, não proporcionam os ganhos desejados.

Contudo, essas iniciativas indicam que há uma preocupação com o estabelecimento de colaboração. As entrevistas indicam que as empresas reconhecem os ganhos potenciais dessas práticas, apesar de ainda terem receio da interdependência entre os elos. Dessa forma, retomando a questão central de pesquisa deste trabalho, pode-se inferir que, no caso estudado, a colaboração ocorre majoritariamente em nível tático. No entanto, estão relativamente distantes da integração estratégica e intangíveis (i.e., interpessoal e cultural).

Como implicações gerenciais da pesquisa realizada, recomenda-se que as empresas invistam principalmente nos elementos de colaboração estratégicos e, principalmente, nos intangíveis. A mudança de uma organização começa pela mudança dos indivíduos que a compõem. Pensar colaborativamente e agir localmente torna-se um imperativo para a maximização da cadeia como um todo.

Um limite desta pesquisa está na ausência de uma discussão sobre os mesmos mecanismos de colaboração na visão da montadora. Há, desta forma, oportunidades de pesquisas futuras de levantamento dos elementos de colaboração, não somente na empresa-foco, mas nas camadas adjacentes da cadeia de suprimentos. Algumas outras questões ainda permanecem sem respostas, como: se o poder de influência das montadoras atingiria os fornecedores de segunda camada e em que grau. Futuras publicações poderão dar continuidade a este trabalho.

\section{Referências}

Almeida, M. M. K., Marins, F. A. S., Salgado, A. M. P., Santos, F. C. A., \& Silva, S. L. (2015). Mitigation of the bullwhip effect considering trust and collaboration in supply chain management: a literature review. The International Journal of Advanced Manufacturing Technology, 77(1), 495-513.

Alves, A. G., Fo., Cerra, A. L., Maia, J. L., Sacomano, M., No., \& Bonadio, P.V.G. (2004). Pressupostos da gestão da cadeia de suprimentos: evidências de estudos sobre a indústria automobilística. Gestão \& Produção, 11(3), 275-288.

Ambrose, E., Marshall, D., \& Lynch, D. (2010). Buyer supplier perspectives on supply chain relationships.
International Journal of Operations \& Production Management, 30(12), 1269-1290. http://dx.doi. org/10.1108/01443571011094262.

Anderson, J. C., \& Narus, J. A. (1990). A modelo of distributor firm and manufactures firm working partberships. Journal of Marketing, 54(1), 42-58. http:// dx.doi.org/10.2307/1252172.

Associação Nacional dos Fabricantes de Veículos Automotores -ANFAVEA (2014). Recuperado em 4 junho de 2014 , de http://www.anfavea.com.br/.

Badenhorst, R. C. (2010). Supply-side aggregation: how collaborations via professional clusters could impact on the freelance management labour supply market in the UK. Cambridge: Henley Business School. http:// dx.doi.org/10.2139/ssrn.1874790.

Barratt, M. (2004). Understanding the meaning of collaboration in the supply chain. Supply Chain Management: An International Journal, 9(1), 30-42. http://dx.doi. org/10.1108/13598540410517566.

Barratt, M., \& Oliveira, A. (2001). Exploring the experiences of collborative planning iniciatives. International Journal of Physical Distribution \& Logistics Management, 31(4), 266-289. http://dx.doi.org/10.1108/09600030110394932.

Bhattacharya, A., Mohapatra, P., Kumar, V., Dey, P. K., Brady, M., Tiwari, M. K., \& Nudurupati, S. S. (2014). Green supply chain performance measurement using fuzzy ANP-based balanced scorecard: a collaborative decision-making approach. Production Planning \& Control: The Management of Operations, 25(8), 698714. http://dx.doi.org/10.1080/09537287.2013.798088.

Blos, M. F., Quaddus, M., Wee, H. M., \& Watanabe, K. (2009). Supply chain risk management (SCRM): a case study on the automotive and electronic industries in Brazil. Supply Chain Management: An International Journal, 14(4), 247-252. http://dx.doi.org/10.1108/13598540910970072.

Bowersox, D.J., Closs, D.J., Cooper, M.B., \& Bowersox, J. C. (2014). Gestão logística da cadeia de suprimentos (4 ed.). Porto Alegre: AMGH.

Cachon, G. P., \& Fisher, M. (2000). Supply chain inventory management and the value of shared information. Management Science, 46(6), 1032-1048. http://dx.doi. org/10.1287/mnsc.46.8.1032.12029.

Cao, M., \& Zhang, Q. (2011). Supply chain collaboration: impact on collaborative advantage and firm performance. Journal of Operations Management, 29(3), 163-180. http://dx.doi.org/10.1016/j.jom.2010.12.008.

Carnevalli, J. A., Miguel, P. A. C., \& Salerno, M. S. (2013). Aplicação da modularidade na indústria automobilística: Análise a partir de um levantamento tipo survey. Production, 23(2), 329-344. http://dx.doi.org/10.1590/ S0103-65132012005000040.

Ceryno, P. S., Scarvada, L. F., Klingebiel, K., \& Yüzgülec, G. (2013). Supply chain risk management: a content analysis approach. International Journal of Industrial Engineering and Management, 4(3), 141-150. 
Charvet, F. F., \& Cooper, M. C. (2011). Key contact employees and supply chain collaboration: a literature review and research agenda. Supply Chain Forum: an International Journal, 12(2), 4-18.

Choi, T. Y., Zhaohui Wu, Ellram, L., \& Koka, B. R. (2002). Supplier-supplier relationships and their implications for buyer-supplier relationships. IEEE Transactions on Engineering Management, 49(2), 119-129. http:// dx.doi.org/10.1109/TEM.2002.1010880.

Ciravegna, L., Romano, P., \& Pilkington, A. (2013). Outsourcing practices in automotive supply networks: an exploratory study of full service vehicle suppliers. International Journal of Production Research, 51(8), 2478-2490. http://dx.doi.org/10.1080/00207543.201 2.746797

Clark, T. H., \& Lee, H. G. (2000). Performance, interdependence and coordination in business-to-business electronic commerce and supply chain management. Information Technology and Management, 1(1-2), 85-105. http:// dx.doi.org/10.1023/A:1019108621684.

Cooper, M. C., Lambert, D. M., \& Pagh, J. D. (1997). Supply chain management: more than a new name for logistics. The International Journal of Logistics Management, 8(1), 7-14. http://dx.doi.org/10.1108/09574099710805556.

Corrêa, H. L. (2010). Gestão de redes de suprimentos: integrando cadeias de suprimento no mundo globalizado. São Paulo: Atlas.

Croxton, K. L., Lambert, D. M., García-Dastugue, S. J., \& Rogers, D. S. (2002). The demand management process. The International Journal of Logistics Management, 13(2), 51-66. http://dx.doi.org/10.1108/09574090210806423.

Danese, P. (2007). Designing CPFR collaborations: insights from seven case studies. International Journal of Operations \& Production Management, 27(2), 181204. http://dx.doi.org/10.1108/01443570710720612.

Dannenberg, J., \& Kleinhans, C. (2007). The coming age of collaboration in the automotive industry: for automakers, it's all about brand management. Mercer Management Journal, 17, 87-94.

Donada, C. (2001). Co-development partnerships: consequences for car suppliers. International Journal Automotive Technology and Managemnet, 1(2/3), 183. http://dx.doi.org/10.1504/IJATM.2001.000034.

Dyer, J. H., \& Chu, W. (1996). The determinants of interfirm trust in supplier automaker relationships in the U.S, Japan and Korea. Journal of International Business Studies, 31(2), 259-285. http://dx.doi.org/10.1057/ palgrave.jibs.8490905.

Esper, T. L. (2007). Intercorporate coordination. In J. T. Mentzer, M. B. Myers \& T. P. Stank (Eds.), Handbook of global supply chain management (Cap. 26, pp. 443454). California: Sage.

Evans, P., \& Wolf, B. (2005). Collaboration rules. Harvard Business Review, 83(7), 96-104. PMid:16028820.
Fawcett, S. E., Magnan, G. M., \& McCarter, M. W. (2008). A three stage implementation model for supply chain collaboration. Journal of Business Logistics, 29(1), 93-112. http://dx.doi.org/10.1002/j.2158-1592.2008. tb00070.x.

Fleury, A. C. C., \& Fleury, M. T. L. (2000). Estratégias empresariais e formação de competências: um quebracabeça caleidoscópio da indústria brasileira. São Paulo: Atlas.

Foroughi, A., Albin, M., \& Kocakulah, M. (2006). Perspectives on global supply chain supply-side risk management. In Proceedings of the Portland International Conference on Management of Engineering and Technology (Vol. 6, pp. 2732-2740). Portland: Portland State University.

Frankel, R., Goldsby, A. B., \& Whipple, J. M. (2002). Grocery industry collaboration in the wake of ECR. International Journal of Logistics Management, 13(1), 57-72. http://dx.doi.org/10.1108/09574090210806360.

Fu, Y., \& Piplani, R. (2004). Supply-side collaboration and its value in supply chains. European. Journal of Operational Research, 152(1), 281-288. http://dx.doi. org/10.1016/S0377-2217(02)00670-7.

Golicic, S. L., \& Vitasek, K. (2007). Interfunctional coordination. In J. T. Mentzer, M. B. Myers \& T. P. Stank (Eds.), Handbook of global supply chain management (Cap. 25, pp. 427-442). California: Sage.

Grackin, A. (2014). Retailer collaboration: managing the supply side. Newton: Chain Link Research. Recuperado em 3 março de 2015, de http://www.clresearch.com/ research/detail.cfm?guid=116DE42D-3048-79ED99D9-A12B90EA50C9.

Gümüş, M., Ray, S., \& Gurnani, H. (2012). Supply-side story: risks, guarantees, competition, and information asymmetry. Management Science, 58(9), 1694-1714. http://dx.doi.org/10.1287/mnsc.1110.1511.

Gunasekaran, A., \& Ngai, E. W. T. (2004). Information systems in supply chain integration and management. European Journal of Operational Research, 159(2), 269-295. http://dx.doi.org/10.1016/j.ejor.2003.08.016.

Hadaya, P., \& Cassivi, L. (2007). The role of joint collaboration planning actions in a demand-driven supply chain. Industrial Management \& Data Systems, 7(7), 954978. http://dx.doi.org/10.1108/02635570710816694.

Handfield, R.B., \& Nichols, E.L. (2002). Supply chain redesing: transforming supply chains into integrated value systems. Nova Jersey: Pearson Education LTD.

Hudnurkar, M., Jakhar, S., \& Rathod, U. (2014). Factors affecting collaboration in supply chain: a literature review. Procedia: Social and Behavioral Sciences, 133(15), 189-202. http://dx.doi.org/10.1016/j.sbspro.2014.04.184.

Humphrey, J. (2003). Globalization and supply chain networks: the auto industry in Brazil and India. Global Networks, 3(2), 121-141. http://dx.doi.org/10.1111/14710374.00053 . 
Ireland, R., \& Bruce, R. (2000). CPFR: only the beginning of collaboration. Supply Chain Management Review, 80-88.

Jabbour, A. B. L. S., Jabbour, C. J. C., Freitas, W. R. S., \& Teixeira, A. A. (2013). Lean and green: Evidências empíricas do setor automotivo brasileiro. Gestão \& Produção, 20(3), 653-665. http://dx.doi.org/10.1590/ S0104-530X2013000300011.

Jayaram, J., Vickery, S., \& Droge, C. (2008). Relationship building, lean strategy and firm performance: an exploratory study in the automotive supplier industry. International Journal of Production Research, 46(20), 5633-5649. http://dx.doi.org/10.1080/00207540701429942.

Kanter, R. M. (1994). Collaborative advantage: the art of aliances. Harvard Business Review, 96-108.

Kersten, W., \& Stengel, D. (2011). Mitigation strategies in global supply chain risk management: an exploratory study. In W. Kersten, T. Blecker \& C. Jahn (Eds.), International supply chain management and collaboration practices (pp. 55-74). Köln: Josef Eul Verlag.

Kwon, I.-W., \& Suh, T. (2004). Factors affecting the level of trust and commitment in supply chain relationships. The Journal of Supply Chain Management, 40(1), 4-14. http://dx.doi.org/10.1111/j.1745-493X.2004.tb00165.x.

Lambert, D. M. (2006). Supply chain management: process, partnerships, performance. Flórida: Supply Chain Management Institute.

Lambert, D. M., \& Knemeyer, A. M. (2004). We're in this together. Harvard Business Review, 114-122.

Lee, C. W., Kwon, I.-W. G., \& Severance, D. (2007). Relationship between supply chain performance and degree of linkage among supplier, internal integration, and customer. Supply Chain Management: An International Journal, 12(6), 444-452. http://dx.doi. org/10.1108/13598540710826371.

Lee, H. L., Padmanabhan, V., \& Whang, S. (1997). Information distorsion in a supply chain: the bullwhip effect. Management Science, 43(4), 546-558. http:// dx.doi.org/10.1287/mnsc.43.4.546.

Liker, J. K., \& Choi, T. Y. (2004). Building deep supplier relationships. Harvard Business Review, 104-113.

Lockström, M., Schadel, J., Harrison, N., Moser, R., \& Malhotra, M. K. (2010). Antecedents to supplier integration in the automotive industry: a multiplecase study of foreign subsidiaries in China. Journal of Operations Management, 28(3), 240-256. http://dx.doi. org/10.1016/j.jom.2009.11.004.

Lusch, R. F., \& Brown, J. R. (1996). Interdependency, contracting, and relational behavior in marketing channels. Journal of Marketing, 60(4), 19-38. http:// dx.doi.org/10.2307/1251899.

Matopoulos, A., Vlachopoulou, M., Manthou, V., \& Manos, B. (2007). A conceptual framework for supply chain collaboration: empirical evidence from the agri-food industry. Supply Chain Management: An
International Journal, 12(3), 177-186. http://dx.doi. org/10.1108/13598540710742491.

Maylett, T., \& Vitasek, K. (2007). For closer collaboration, try education. Supply Chain Management Review, 11(1), 58.

McClellan, M. (2001). Automotive industry collaboration (Collaborative Manufacturing Whitepaper Series). Collaboration Synergies. Recuperado em 27 de fevereiro de 2015, de www.cosyninc.com.

Mehrjerdi, Y. Z. (2009). The collaborative supply chain. Assembly Automation, 29(2), 127-136. http://dx.doi. org/10.1108/01445150910945589.

Melo, D. C., \& Alcântara, R. L. C. (2012). Proposição de um modelo para a gestão da demanda: um estudo entre os elos atacadista e fornecedores de produtos de mercearia básica. Gestão \& Produção, 19(4), 759-777. http://dx.doi.org/10.1590/S0104-530X2012000400008.

Mentzer, J. T., Moon, M. A., Estampe, D., \& Margolis, G. W. (2007). Demand management. In J. T. Mentzer, M.B. Myers \& T. P. Stank (Eds.), Handbook of global supply chain management (pp. 65-85). Sage: London.

Mentzer, J.T., DeWitt, W., Keebler, J. S., Min, S., Nix, N. W., Smith, C. D., \& Zacharia, Z. G. (2001). Defining supply chain management. Journal of Business Logistics, 22(2), 1-25.

Mesquita, M. A., \& Castro, R. L. (2008). Análise das práticas de planejamento e controle da produção em fornecedores da cadeia automotiva brasileira. Gestão \& Produção, 15(1), 33-42.

Min, S. (2001). Inter-functional coordination in supply chain management. In J. T. Mentzer (Ed.), Supply chain management (Cap. 15, pp. 391-410). California: Sage.

Mohr, J., \& Spekman, R. (1994). Characteristics of partnership success: partnership atributes, communication behavior, and conflict resolution techniques. Strategic Management Journal, 15(2), 135-152. http://dx.doi. org/10.1002/smj.4250150205.

Moreira, N., Santa-Eulalia, L. A., Ait-Kadi, D., WoodHarper, T., \& Wang, Y. (2015). A conceptual framework to develop green textiles in the aeronautic completion industry: a case study in a large manufacturing company. Journal of Cleaner Production, 105(15), 371-388. http:// dx.doi.org/10.1016/j.jclepro.2014.09.056.

Morgan, R. M., \& Hunt, S. D. (1994). The commitment: trust theory of relationship marketing. Journal of Marketing, 58(3), 20-38. http://dx.doi.org/10.2307/1252308.

Munhoz, A., \& Vieira, G. E. (2009). Análise de estratégias colaborativas em uma cadeia de suprimentos do setor automotivo. In Anais do XII Simpósio de Administração da Produção, Logística e Operações Internacionais (Vol .6, pp. 1-15). São Paulo: FGV.

Nesheim, T. (2001). Externalization of the core: antecedentes of collaborative relationships in cloting supply chains. European Journal of Purchasing and Supply 
Management, 7(4), 217-225. http://dx.doi.org/10.1016/ S0969-7012(01)00003-X.

Neumann, D. (2012). Collaborative systems: a systems theoretical approach to interorganizational collaborative relationships. Peterlang: Frankfurt. 293 p.

Neumann, D., Santa-Eulalia, L. A., \& Zahn, E. (2011). Towards a theory of collaborative systems. In L. M. Camarinha-Matos, A. Pereira-Klen \& H. Afsarmanesh (Eds.), Adaptation and value creating collaborative networks (IFIP Advances in Information and Communication Technology, 362, pp. 306-313). New York: SpringerVerlag Berlin Heidelberg.

Oh, J., \& Rhee, S. (2008). The influence of supplier capabilities and technology uncertainty on manufacturessupplier collaboration: a study of Korean automotive industry. International Journal of Operations \& Production Management, 28(6), 490-517. http://dx.doi. org/10.1108/01443570810875331.

Pereira, M. M., \& Amatucci, M. (2014). Local and global influences on the social responsibility performance of multinational corporations in the Brazilian automotive industry. International Journal of Automotive Technology and Management, 14(2), 121-137. http://dx.doi. org/10.1504/IJATM.2014.060750.

Pires, S. R. I. (1998). Managerial implications of the modular consortium model in a Brazilian automotive plant. International Journal of Operations \& Production Management, 18(3), 221-232. http://dx.doi. org/10.1108/01443579810368290.

Popp, R. (2000). Swamped in information, but starved of data: information and intermediaries in clothing supply chains. Supply Chain Management Review, 5(3), 28-36.

Ramanathan, U., \& Gunasekaran, A. (2014). Supply chain collaboration: impacto of sucess in long-term partnerships. International Journal of Production Economics, 147, 252-259. http://dx.doi.org/10.1016/j.ijpe.2012.06.002.

Rapp, A., Beitelspacher, L. S., Schillewaert, N., \& Baker, T. L. (2012). The differing effects of technology on inside vs. outside sales forces to facilitate enhanced customer orientation and interfunctional coordination. Journal of Business Research, 65(7), 929-936. http:// dx.doi.org/10.1016/j.jbusres.2011.05.005.

Rodrigues, D. M., \& Sellitto, M. A. (2008). Práticas logísticas colaborativas: o caso de uma cadeia de suprimentos da indústria automobilística. Revista de Administração, 43(1), 97-111.

Roldan, F., \& Miyake, D. I. (2004). Mudanças de forecast na indústria automobilística: iniciativas para a estruturação dos processos de tomada de decisão e processamento da informação. Gestão \& Produção, 11(3), 413-427. http://dx.doi.org/10.1590/S0104-530X2004000300013.

Roldan, L. B., Hansen, P. B. \& Dale, L. B. (2011). Modelo de identificação de fatores críticos de sucesso na gestão de cadeias de suprimentos. In Anais do XIV Simpósio de Administração da Produção, Logística e Operações Internacionais. São Paulo: FGV.

Ryu, I., So, S., \& Koo, C. (2009). The role of partnership in supply chain performance. Industrial Management \& Data Systems, 109(3-4), 496-514. http://dx.doi. org/10.1108/02635570910948632.

Sacomano, M., No., Pires, S. R. I., \& Silva, E. M. (2013). Modularity and Relational mechanisms of governance: an analysis of modular consortium and industrial condominium. Journal of Operations and Supply Chain Management, 6, 74-90.

Sambasivan, M., Siew-Phaik, L., Mohamed, Z. A., \& Leong, Y. C. (2011). Impact of interdependence between supply chain partners on strategic alliance outcomes: Role of relational capital as a mediating constructo. Management Decision, 49(4), 548-569. http://dx.doi. org/10.1108/00251741111126486.

Sandberg, E. (2007). Logistcs collaboration in supply chains: practice vs. theory. International Journal of Logistics Management, 18(2), 274-293. http://dx.doi. org/10.1108/09574090710816977.

Schiele, H. (2010). Early supplier integration: the dual role of purchasing in new product development. $R$ \& D Management, 40(2), 138-153. http://dx.doi. org/10.1111/j.1467-9310.2010.00602.x.

Simatupang, T. M., \& Sridharan, R. (2002). The collaborative supply chain. International Journal of Logistics Management, 3(1), 15-30. http://dx.doi. org/10.1108/09574090210806333.

Simatupang, T. M., \& Sridharan, R. (2005). The collaboration index: a measure for supply chain collaboration. Benchmarking: An International Journal, 35(1), 44-62.

Simchi-Levi, D., Kaminsky, P., \& Simchi-Levi, E. (2010). Cadeia de suprimentos: projeto e gestão: conceitos, estratégias e estudos de caso. Porto Alegre: Bookman.

Skjoett-Larsen, T., Thernoe, C., \& Andresen, C. (2003). Supply Chain Collaboration: as empirical evidence. International Journal of Physical Distribution \& Logistics Management, 33(6), 31-49. http://dx.doi. org/10.1108/09600030310492788.

Sodhi, M. S., \& Son, B.-G. (2009). Supply-chain partnership performance. Transportation Research Part E: Logistics and Transportation Review, 45(6), 937-945. http:// dx.doi.org/10.1016/j.tre.2009.05.004.

Sousa, C. M. P., \& Lengler, J. (2011). Examining the determinants of interfunctional coordination and export performance: An investigation of Brazilian exporters. Advances in International Marketing, 21, 189-206. http:// dx.doi.org/10.1108/S1474-7979(2011)0000021011.

Thomé, A. M. T., Scarvada, L. F., Pires, S. R. I., Ceryno, P., \& Klingebiel, K. (2014). A multi-tier study on supply chain flexibility in the automotive industry. International Journal of Production Economics, 158, 91-105. http:// dx.doi.org/10.1016/j.ijpe.2014.07.024. 
Thun, J.-H., \& Hoenig, D. (2011). An empirical analysis of supply chain risk management in the German automotive industry. International Journal of Production Economics, 131(1), 242-249. http://dx.doi.org/10.1016/j. ijpe.2009.10.010.

Vanalle, R. M., \& Salles, J. A. A. (2011). Relação entre montadoras e fornecedores: modelos teóricos e estudos de caso na indústria automobilística brasileira. Gestão \& Produção, 18(2), 237-250. http://dx.doi.org/10.1590/ S0104-530X2011000200002.

Vereecke, A., \& Muylle, S. (2006). Performance improvement through supply chain collaboration in Europe. International Journal of Operations \& Production Management, 26(11), 1176-1198. http:// dx.doi.org/10.1108/01443570610705818.

Vieira, J. G. V., Yoshizaki, H. T. Y., \& Ho, L. L. (2009). Um estudo sobre colaboração logística entre indústria de bens de consumo e redes de varejo supermercadista. Gestão \& Produção, 16(4), 556-570. http://dx.doi. org/10.1590/S0104-530X2009000400006.

Vieira, J. G. V., Yoshizaki, H. T. Y., \& Lustosa, L. J. (2010). Um estudo exploratório sobre colaboração logística num grande varejo supermercadista. Produção, 20(1), 135-147.

Vivaldini, M., Souza, F. B., \& Pires, S. R. I. (2008). Implementação de um sistema Collaborative Planning,
Forecasting and Replenishiment em uma grande rede de fast food por meio de um prestado de serviço logístico. Gestão \& Produção, 15(3), 477-489. http://dx.doi. org/10.1590/S0104-530X2008000300005.

Whipple, J. M., \& Russell, D. (2007). Building supply chain collaboration: a tipology of collaborative approaches. International Journal of Logistics Management, 18(2), 174-196. http://dx.doi.org/10.1108/09574090710816922.

Wu, I.-L., Chuang, C.-H., \& Hsu, C.-H. (2014). Information sharing and collaborative behaviors in enabling supply chain performance: A social exchange perspective. International Journal of Production Economics, 148, 122-132. http://dx.doi.org/10.1016/j.ijpe.2013.09.016.

Xu, K., \& Dong, Y. (2004). Information gaming in demand collaboration and supply chain performance. Journal of Business Logistics, 25(1), 121-144. http://dx.doi. org/10.1002/j.2158-1592.2004.tb00172.x.

Yin, R. K. (2003). Applications of case study research (2 ed.). London: SAGE Publications.

Zeng, Y., Wang, L., Deng, X., Cao, X., \& Khundker, N. (2012). Secure collaboration in global design and supply chain environment: problem analysis and literature review. Computers in Industry, 63(6), 545-556. http:// dx.doi.org/10.1016/j.compind.2012.05.001. 